\title{
Do plants and animals differ in phenotypic plasticity?
}

\author{
RENEE M BORGES \\ Centre for Ecological Sciences, Indian Institute of Science, Bangalore 560 012, India \\ (Fax, 91-80-23601428; Email, renee@ces.iisc.ernet.in)
}

\begin{abstract}
This paper compares the flexibility in the nexus between phenotype and genotype in plants and animals. These taxa although considered to be fundamentally different are found to be surprisingly similar in the mechanisms used to achieve plasticity. Although non-cognitive behaviour occurs in plants, its range is limited, while morphological and developmental plasticity also occur to a considerable extent in animals. Yet both plants and animals are subject to unique constraints and thus need to find unique solutions to functional problems. A true comparison between the plant and animal phenotype would be a comparison between plants and sessile photosynthesizing colonial invertebrates. Such comparisons are lacking. However, they would provide important insights into the adaptive significance of plasticity in these groups. It is also suggested that a comparison of inflexible traits in these groups would provide an understanding of the constraints, as well as the costs and benefits, of a plastic versus non-plastic phenotype in plants and animals.
\end{abstract}

[Renee M Borges 2005 Do plants and animals differ in phenotypic plasticity?; J. Biosci. 30 41-50]

\section{Introduction}

It is not my intention to review the phenomenon of phenotypic plasticity in plants or in animals since excellent recent reviews exist (Pigliucci 1996; Sultan 2000; Agrawal 2001; Givnish 2002; Grime and Mackey 2002; Novoplansky 2002; Sachs 2002; Schlichting and Smith 2002; Stamps 2003; West-Eberhard 2003). However, I will attempt in this paper to present some important similarities and differences between plants and animals and the consequences thereof for plasticity. This is especially germane in view of the many recent exciting findings at the organismal and molecular level about the responses of plants and animals to various stimuli. As our understanding of the origin and evolution of developmental processes improves, and our ability to track signal transduction pathways is being refined, it appears that the distinction between plants and animals at many levels is becoming blurred despite their brief common lineage and subsequent millennia of independent evolution (Meyerowitz 1999, 2002).

An essential divide between plants and animals has often been taken to be the absence of behaviour in the one and the presence of behaviour in the other. However, if behaviour is defined as the response of an organism to a stimulus, then plants do behave, and this divide disappears. Furthermore, if behaviour is defined as phenotypic plasticity that is expressed within the lifetime of an individual, then plants certainly show behaviour albeit of a non-cognitive nature (Silvertown 1998). In a seminal review, Silvertown and Gordon (1989) outlined a framework for plant behaviour in which they presented various properties of stimuli and the abilities of plants to respond to them. In their scheme, it is evident that pattern is the only type of stimulus property to which plants do not respond. In the absence of a nervous system which can store a pattern, matching a pattern to an innate or acquired template is not possible in plants. Yet, a sign of the changing perspectives on plants is that the lexicon to describe plant responses now routinely incorporates words formerly confined to animals such as foraging (Kelly 1990) and displaying (Borges et al 2003; Somanathan et al 2004).

In the following sections, I will present instances of unexpected plasticity and unexpected sensitivity to stimuli in both plants and animals, which will help to highlight the similarities and differences in phenotypic plasticity between these taxa.

\section{Can plants talk? And if plants can talk, can they also hear?}

Plants are now known to respond to volatile signals produced by other plants, and therefore, to communicate

Keywords. Epigenetic inheritance; plant behaviour; plant communication; polyphenism; reaction norm 
(Farmer and Ryan 1990; Karban et al 2000). Until recently, this ability was seriously discredited. For example, in their review, Silvertown and Gordon (1989) remarked: "The claim by Baldwin and Schultz (4) [1983] that trees are able to communicate, if true, would point to the first example of an exchange of signals between plants; however, Fowler and Lawton (21) [1985] have seriously doubted the evidence." This was followed by a subsequent debate around the issue of whether plants can "hear" even though they might be able to "talk" (Firn and Jones 1995; Bruin et al 1995) and whether talking and listening were realistic possibilities under field or non-laboratory conditions given the known sensitivities of plants and their lack of specialized sensory "organs". It was also important to consider whether the information content about the risk of herbivory to neighbouring plants or adjacent parts of the same plant was reliable enough and whether the induced defence could be mounted rapidly enough to result in strong selection for the evolution of plastic responses by induced defences instead of via constitutive protection (Karban et al 1999). The evaluation of the costs and benefits of induced defences was thus necessary from both proximal as well as ultimate perspectives. Carefully done experiments under field situations have now unambiguously established that plants not only talk but they also listen, as evidenced from the increase in polyphenol oxidase and other oxidative enzymes in the defence repertoire of tobacco plants when exposed to an epimer of methyl jasmonate released by neighbouring sagebrush plants that were clipped to simulate herbivory (Karban et al 2000) and of black alders when exposed to a signal consisting of ethylene and a mixture of terpenes produced by alders under herbivore attack (Tscharntke et al 2001). This communication between plants about their attacked status can also occur via roots or mycorrhizae (Simard et al 1997). Yet, detractors of the plant communication hypothesis still exist (e.g. Lerdau 2002). Microarray analysis is now revealing the complex signal transduction networks involved in induced defence pathways in plants after exposure to the volatile signalling molecules methyl jasmonate or ethylene in the model plant Arabidopsis thaliana (Schenk et al 2000). Thus ecologists, phytopathologists and molecular biologists are confirming that plants can not only talk, but they can hear, and many use the same language.

\section{Can plants see?}

Vision and light reception play important and undisputed roles in behavioural and physiological processes in animals leading to plasticity of responses to biotic and abiotic factors such as predation threats or photoperiodic changes. In recent years, it has become apparent that plants have acute abilities to sense their light environments. A system of three types of photoreceptors - phytochromes, cryptochromes, and phototropin - ensures that plants can sense the proximity of their neighbours and modify their growth and development in the form of a shade-avoidance response, if appropriate (Ballaré 1999; Smith 2000). Plants are, however, unique in the sense that during this process of growth towards light, they also cause self-shading. Thus, individual modules of plants have a unique environmental history which is a sum total of "external" as well as "internal" factors. The response to red: far red light reflectance or blue light gradients are used by plants to track gaps in the canopy towards which they can grow (Ballaré 1999; Lin 2000; Fankhauser 2002). These lightrelated stimuli are also used to determine such events as when plants should break bud dormancy, or when they should flower, and thus to regulate physiological and developmental processes (Horvath et al 2003). Smith (2000) speculates that the ability of plants to sense and respond in complex ways to their light environment may have contributed to the rise and diversification of the angiosperms. Thus, plants use their light sensory mechanisms to forage for light and show growth responses in the direction of light or away from light (scototropism) as occurs in seedlings of climbers that need to grow towards potential tree trunk supports (Strong and Ray 1975). Plants can also optimize light capture within stationary cells by the internal movement of chloroplasts in response to light (Kasahara et al 2002). The above-ground response of plants to light is also mirrored by below-ground responses of the roots to nutrient gradients. Roots exhibit branching and increased or decreased root biomass as a result of feedback from foraging success (Grime et al 1991). It is now known that an $\mathrm{NO}_{3}^{-}$inducible MADS box gene ANR1 is responsible in Arabidopsis for lateral root proliferation in $\mathrm{NO}_{3}^{-}$rich soil patches (Zhang and Forde 1998). A similar stimulus-response system could explain stem preferences of the parasitic plant Cuscuta for specific host plants (Kelly 1992; Trewavas 2002).

Plant foraging has been shown to be predictable from the marginal value theorem (Kelly 1990) that was developed to examine optimal behaviour in animals foraging within and between resource patches (Charnov 1976). A plasticity of responses to resource gradients is also shown by primitive amoeboid slime moulds which exhibit mazesolving abilities to find the shortest path between two food sources (Nakagaki et al 2000). Is there, however, a difference between root and shoot foraging of plants and that of an animal as primitive as a slime mould? One major difference is that the cost to plants of making a mistake by growing in the wrong direction or of investing growth in a direction whose resource value diminishes rapidly with time is potentially higher than that for animals since mobile animals can reverse direction of move- 
ment albeit with loss of energy. Plants, on the other hand, cannot often resorb all the nutrients that they have already committed to the structures required for above- or below-ground foraging in particular directions. As Trewavas (2003) points out, plants have capitalized on the free availability of light as an energy source and, unlike animals, have consequently given up "movement". Moreover, whatever movement plants perform results from growth and development.

\section{Morphological and developmental plasticity in animals}

With their modular construction, plants have usually been considered to have greater plasticity than animals in morphological and developmental responses to changes in their biotic and abiotic environments. However, besides positive or negative taxis, animals can also cope with biotic stresses, such as the presence of neighbours, by exhibiting responses that involve morphological change. The best known example of density-related polymorphism in animals is the colour polyphenism of the adult desert locust Schistocerca gregaria (Wilson 2000) in which the solitary form is cryptic while the gregarious form is conspicuous and aposematic. Although this polymorphism is due to selection for the appropriate adult colour morph at different densities and is thus, a true polyphenism, studies on Schistocerca emarginata indicate that this colour change can occur in a single generation via density effects on cuticular melanization of successive nymphal instars, thus representing a true phenotypic plasticity in response to crowding (Sword 1999, 2002). The diapausing dauer larva of Caenorhabditis elegans is another example of a developmental response to increased concentrations of a "crowding" pheromone (Golden and Riddle 1984).

Plants are typically known to show the phenomenon of die-back and recovery when exposed to stress, while animals were believed to be incapable of such responses. While animals were thought to have fixed sizes (heights, lengths) on reaching maturity, studies are now indicating that adult animals can increase and decrease body size based on crowding-related stress (Piersma and Drent 2003). For example, even animals such as adult sea urchins that have a hard calcium-based skeleton can both increase as well as decrease in size based on whether they are grown under crowded or non-crowded conditions (Levitan 1989) and marine iguanas have been recorded to become smaller by as much as $20 \%$ after an El Niño Southern Oscillation (ENSO) event (Wikelski and Thom 2000).

Animals can possibly demonstrate as much developmental plasticity as plants in response to specific chemical or physical signals. An excellent recent example is of the polyembyronic parasitoid wasp Copidosoma floridanum (Harvey et al 2000). In this species, the caste ratio of reproductive to soldier larvae shifts in favour of the soldier caste only if heterospecific larvae of the competing parasitoid Microplitis demolitor are developing syntopically within the same lepidopteran host body. These aggressive soldier larvae attack and kill the heterospecific larvae, thus ensuring the survival of sufficient numbers of their own clones. Similarly, Cardiocondyla ants in which males are usually wingless, produce winged dispersing males in response to environmental stress (Cremer and Heinze 2003). Conditions during post-natal development can also selectively affect the gross morphology of body parts in animals as has been demonstrated in the lizard Anolis sagrei wherein hatchlings reared in environments with access to locomotion on either broad or narrow surfaces had correspondingly broad or narrow hindlimbs that gave them either enhanced sprint speed or greater manœuverability as needed on their respective locomotory surfaces (Losos et al 2000).

\section{Transgenerational transfer of phenotypic changes in plants and animals}

Various "Lamarckian" mechanisms of inheritance of phenotypic changes have been found to occur in both plants and animals (Jablonka et al 1998); these have also been recorded to extend to the F2 generation in animals (Agrawal et al 1999). A grandmother effect was thus observed in Daphnia in which the trend towards large helmets induced in response to a predator kairomone in the parental generation, continued into the F2 generation even after removal of the kairomone in the F1 generation (Agrawal et al 1999). A transgenerational effect was also reported in the radish Raphanus raphanistrum wherein F1 seedlings had upregulated levels of hydroxylated glucosinolates as a consequence of herbivory by specialist caterpillars on their mothers; however, in this case the effect did not persist into the F2 generation (Agrawal et al 1999). Epigenetic factors that act via multiple modalities to influence phenotypes across generations are also well illustrated in the effect of male attractiveness on differential deposition of testosterone in the eggs of the zebra finch. Females mated with highly attractive males deposited greater amounts of both testosterone and $5 \alpha$-dihydrotestosterone in their eggs with important consequences on the development of the chicks (Gil et al 1999).

\section{Neuronal plasticity in animals and learning in plants}

The neural networks of animals are subject to reinforcement and remodelling based on the strength of the stimuli 
and the frequency with which they are presented. Although neuronal plasticity has long been recognized, it is only with bird systems that extensive neural recrudescence has been demonstrated (Nottebohm 1981). Avian song control systems exhibit seasonal plasticity leading to dramatic increases or decreases in the volumes of entire brain regions under the influence of the photoperiod and its consequent impact on circulating levels of sex steroids (Tramontin and Brenowitz 2000). Furthermore, animals, with their neural networks, are capable of learning. In recent years, the molecular mechanisms of memory are being elucidated (reviewed in Kandel 2001; Greengard 2001). Implicit short-term memory involving reflexes has been shown in the marine sea-slug Aplysia to involve persistent protein kinase activity and secondmessengers such as cAMP and $\mathrm{Ca}^{2+} /$ calmodulin, while longer-term memory involves persistent activation of kinases such as mitogen-activated protein (MAP) kinases (Bliss and Collingridge 1993). Bhalla and Iyengar (1999) and Bhalla et al (2002) have shown computationally as well as experimentally that connections between preexisting signalling pathways can confer emergent properties on entire networks that are not possessed by individual circuits alone; furthermore, the previous history of the stimulus can influence subsequent responses of the system to new stimuli. Thus, for example, extended signal duration (e.g. sustained calmodulin kinase [CAMKII] activation) after the initial stimulus $\left(\mathrm{Ca}^{2+}\right)$ was terminated was one emergent property of such networks. Furthermore, in the MAP kinase system, if the initial stimulus was below a certain threshold, it could not elicit a sustained response, while if this initial low response was followed by a suprathreshold stimulus, a molecular "switch" was thrown such that a sustained response was achieved. Thus the circuit responds in a way that reflects the prior history and thus the "memory" of the stimulus (Ingolia and Murray 2002). Bray (1995) believes that, in simple unicellular organisms, protein circuits act instead of nervous systems to control behaviour. These circuits can act as computational units or artificial neurons (perceptrons) with cross-talk properties and communication gates that use Boolean logic (Bray 1995; Genoud and Métraux 1999).

What are the implications of these findings for stimulus-response functions in plants? Do plants have memory? Can plants learn? According to Trewavas (1999a), they do. This author draws parallels between signaltransduction networks and neural networks in terms of learning and storage of information and likens a calcium wave to the operation of a neural network (Trewavas 1999b). Such a parallel was also drawn by Bhalla and Iyengar (1999). The plasma membrane-based COP9 signalosome in plants is, for example, a signal-transduction cassette or transducon involved in responses to light; furthermore, it is also present in animals where it is invol- ved in MAP kinase signalling (Karniol and Chamovitz 2000). Trewavas and Malhó (1997) and Gilroy and Trewavas (2001) speculate that such transducons could serve as information integration and information storage facilities in plant cells and that the plasma membrane with its signalling cassettes could serve as the computational processor of the cell. Furthermore, Bhalla and Iyengar (1999) demonstrated that the emergent properties of signalling networks were enhanced by isoforms, e.g. isoforms of adenylate cyclase (AC1 and AC2) which are CAMstimulated. Unlike animals, plants are known to have many isoforms of calmodulin, e.g. 13 isoforms in wheat (Yang et al 1996), each of which are probably associated with separate kinases (Harmon et al 2000), thus providing for specificity of encoding information. This gives additional support to the possibility of information storage and thus a form of "memory" and "learning" in plants (Trewavas 1999a,b, 2003). Thus, for example, plants subjected to a hypo-osmotic shock in the absence of $\mathrm{Ca}^{2+}$ will show no physiological response until $\mathrm{Ca}^{2+}$ is added to the medium which could be as long as $20 \mathrm{~min}$ after the shock (Takahashi et al 1997). It appears that some information about the signal is "stored" and then "retrieved" when $\mathrm{Ca}^{2+}$ is available (Trewavas 2003). Guard cell closure in Arabidopsis was also found to be responsive to $\mathrm{Ca}^{2+}$ oscillation kinetics, with short-term closure occurring rapidly irrespective of the $\mathrm{Ca}^{2+}$ oscillation kinetics while long-term closure depended on the number, frequency, amplitude and duration of $\mathrm{Ca}^{2+}$ transients; thus $\mathrm{Ca}^{2+}$ oscillation kinetics can encode valuable information in plant cells that can generate variable physiological responses (Allen et al 2001). Thus, the phenotype of a plant "represents the indissoluble linkage between genes, which can be thought of as a kind of read only memory (ROM), and the signalling networks, which are the biological equivalent of random access memory (RAM). The keys are punched by environmental and developmental cues (Trewavas and Malhó 1997)".

The calcium and calmodulin-mediated signal network is now known to be implicated in responses to diverse environmental stimuli in plants (Yang and Pooviah 2003). Similarities between plants and animals in their receptor kinase signalling pathways also exist and despite their early divergence and distinct molecular mechanisms, both plant and animal signalling systems have mechanistic similarities (Cock et al 2002). For example, calcineurin $\mathrm{B}$-like proteins have been found in plants and are similar to neuronal cytosol $\mathrm{Ca}^{2+}$ sensors involved in neurotransmitter release (Trewavas 1999a). In plants, cytoskeletal elements connected to the plasma membrane are also believed to contain mechanosensitive $\mathrm{Ca}^{2+}$-gated channels (Fasano et al 2002). Although not specifically stated, it is not inconceivable that cytoskeletal deformation can retain memory of the stimulus and thus maintain a re- 
sponsive state even after the stimulus is removed. Furthermore, plant cortical microtubules are now known to play an important role in signal transduction and thus in the responsiveness of plants to the environment (Wasteneys 2003; Wasteneys and Galway 2003). Microtubules in Arabidopsis roots undergo glutamate-mediated depolymerization associated with plasma membrane depolarization in response to an aluminum signal (Sivaguru et al 2003), while microtubule disassembly is implicated in cold acclimation in plants (Abdrakhamanova et al 2003).

In animals, direct cell-cell communication is through gap junctions via small molecules (usually $\leq 1.5 \mathrm{kDa}$ ), or through ligands from secretory vesicles that attach to receptors on the cell. However, in plants, the presence of a symplast, i.e. large gaps in cell walls, allows for even RNA movement between cells. Plasmodesmata and phloem in plants thus form a cytoplasmic network allowing peptide, RNA and hormone trafficking between remote areas of plants. Knowledge of the functioning of this symplastic network is contributing to an understanding of how signals may be effectively and efficiently transferred in time and space in plants despite the absence of a nervous or circulatory system as present in animals ( $\mathrm{Wu}$ et al 2002; Ding et al 2003). Lev-Yadun (2001) has, however, proposed that an analog of dendritic and axonal growth occurs in plants during intrusive growth of certain cellular elements wherein cell extensions can grow to new locations through intervening tissue. Some cells can reach several metres in length. There is also now an emerging view that plasmodesmata are in fact gateable entities supported by actin- and myosin-based cytoskeletal elements; furthermore, the exciting discovery of intercellular cytoskeletal channels in animals cells (recently named tunnelling nanotubes) seems to also throw up the possibility that both plants and animals are supracellular entities (Baluška et al 2004).

\section{Acquisition of immunity in plants and animals}

The immune systems of many animals, especially vertebrates, allows for multiple combinations of antibodyspecifying genes resulting in a highly variable acquired defence system. Plants have been considered rather undeveloped in this regard with a fixed repertoire of resistance $(\mathrm{R})$ genes having receptor-like products that appear to function similarly to the innate immune system of animals (Holt et al 2003; Schulze-Lefert 2004). However, plants are considered somatic genetic mosaics as a result of somatic mutations and recombination in response to abiotic stress with different modules of a single plant having different combinations of resistance genes resulting from their prior exposure to stress. Pineda-Krch and Fagerström (1999) believe that this chimaeric state coupled with intraorganismal selection may actually protect plants from the operation of Muller's ratchet. Furthermore, intraorganismal selection could also facilitate the propagation of successful modules and thus sustain the longevity of trees and of colonial creeping perennials and protect them from "ageing" (Thomas 2002). Plasticity via somatic mutation in response to biotic attack was only recently demonstrated by Lucht et al (2002) in Arabidopsis and by Kovalchuk et al (2003) who showed unambiguously that exposure to pathogens such as the tomato mosaic virus (TMV) in the Havana 425 cultivar of Nicotiana tabacum resulted in the generation of a systemic plant signal that triggered somatic DNA recombinations in both infected and non-infected tissue. Kovalchuk et al (2003) speculate that this systemic recombination signal (SRS) may be related to the signal implicated in systemic acquired resistance (SAR) in plants (Dempsey et al 1999; Dong 2001).

\section{Buffering against phenotypic change in plants and animals}

In plants and in animals, the adaptive nature of plasticity has always been controversial, since the entire reaction norm of the species need not fall within adaptive space (Via et al 1995). This means that it is premature to assume that all phenotypically plastic responses are necessarily adaptive. Few empirical studies have addressed this issue primarily because plasticity itself can prevent the expression of certain phenotypes in altered environments. Thus, it would be impossible to test for the impact of a non-plastic response. It is only recently that approaches to investigating adaptive plasticity are being explored using mutants and transgenic plants (reviewed in Schlichting and Pigliucci 1998; Schmitt et al 1999). Furthermore, the distinction between "true plasticity" and metamorphosis must be carefully made (Diggle 1997, 2002).

If one side of the coin is the generation of adaptive phenotypic diversity, then the other side is buffering against phenotypic change, especially if this change results from stochastic processes and environmental stresses. Considering the similarities already evident between the plasticity-generating mechanisms and the degree of phenotypic responses in plants and animals, it is not surprising therefore that plants (Queitsch et al 2002) and animals (Rutherford and Lindquist 1998) have been found to use heat-shock proteins not only to protect themselves from environmental stress but also perhaps to buffer themselves against the expression of undesirable genetic variation. Mutations in the Hsp90 region have led to the uncovering of "cryptic" genetic variation in both Drosophila and Arabidopsis and even to gross abnormalities, and thus to questions about whether this accumulation of cryptic genetic variation is merely a by-product of the 
normal biochemical function of the Hsp90 chaperone (Mitchell-Olds and Knight 2002; Pigliucci 2002) or whether it has been actively selected for as a capacitor of evolutionary change (Queitsch et al 2002; Sangster et al 2004). The vehicles of phenotypic plasticity in both plants and animals are often products of regulatory genes. The impact of regulatory molecules in the generation of variation in form has been amply demonstrated in an evolutionary lineage of plants that shows enormous levels of variation in morphology. In the Hawaiian silversword alliance (Asteraceae: Helianthaceae-Madiinae) there has been considerable adaptive radiation relative to their North American relatives, i.e. tarweeds. When the tarweeds were compared with the silverswords, this rapid diversification was found to be correlated with accelerated evolution of only regulatory genes whereas there was no difference in mutation rates of neutral genes between the two groups (Barrier et al 2001).

With their modular and indeterminate growth, plants may be expected to have considerable buffering capacity against developmental abnormalities. This capacity in some cases may even exceed that of animals in which development is often sensitive to perturbations, especially to mutations in genes controlling tissue-specific transcription factors (e.g. von Strandmann et al 1997). A study by Schnittger et al (1998) showed that transgenic plants (35S::GL1 try transgenic Arabidopsis) can produce trichomes even from sub-epidermal cells (i.e. from a different cell layer) although they are specified and produced by epidermal cells in the wild type. Furthermore, the distribution pattern of these trichomes of subepidermal and thus ectopic origin was no different from that of trichomes in the wild type suggesting that cell type specification can override tissue-specific signals. Thus the same cell type with normal wild type patterning can be formed from two different germ layers and thus from different cell lineages. It is therefore extremely interesting that animals in which totipotent or pluripotent cells are found tend to be sessile plant-like animals such as sponges, bryozoans and cnidarians (Buss 1987; Money 2002).

\section{Are plants and animals then fundamentally different or surprisingly similar in phenotypic plasticity?}

Bradshaw (1965) made a series of predictions vis-à-vis the response of plants to stress compared to that of animals. He suggested, for example, that plants should be more plastic than animals, that they should have broader tolerance ranges than animals, that they should show stronger inducible defences than animals, and finally that selection pressures for coping with stress should be stronger on plants than on animals because plants are handicapped by their immobility and lack of behavioural responses. Considering the fast accumulating wealth of information on plant sensory abilities and their noncognitive behaviour as well as their rapidly induced responses, it is necessary to review these predictions and evaluate their generalities as was attempted recently by Huey et al (2002). These authors found that in keeping with Bradshaw's prediction, the phenology of physiological events in plants responded to a greater extent to climate change than that of animals. They also attempted a comparison of "plant-like" animals with "true" animals, and found that the distribution of sessile plant-like intertidal invertebrates was more sensitive to temperature than was that of mobile invertebrates.

Sachs (2002) pointed out that there are three fundamental differences in the way plants and animals are organized, and that these differences dictate how they function and thus ultimately affect the plasticity of their responses to new conditions. Firstly, plants continually develop new organs during their lifespan. Thus older modules coexist with juveniles. This modular and indeterminate development provides enormous scope for adopting different developmental strategies under diverse conditions. Secondly, plants can assimilate nutrients from both above and below ground, i.e. from diverse strata, unlike animals that have usually only one nutrient intake point within a single stratum, unless they are sponges, coral-forming colonial coelenterates, or other sessile invertebrates that are, in certain aspects, more like plants than animals. Thus it is possible that root foraging could compete with above-ground foraging in plants, creating a local conflict of interest. Thirdly, plants exhibit considerable redundancy in their organs, e.g. many multiples of leaves, flowers, shoots and roots. Plants have therefore to maintain a co-ordination between these organs, each of which is capable of a relatively independent existence. Trewavas (2003) refers to a "democratic confederation of modules" in plants which is reminiscent of Leigh's parliament of genes (Leigh 1977). How plants integrate the competing demands of the various modules and what is therefore the unit at which plasticity is to be measured are issues that are open to debate.

\section{Do plants and animals differ in constraints on plasticity?}

Are there constraints on plasticity in plants and animals and some types of traits that are relatively more or less fixed compared to others? For example, floral traits, especially in those plants that require specialized pollinator services, should be relatively more fixed to facilitate efficient flower recognition and handling by specialized pol- 
linators. This generally appears to be the case for floral characters (Cresswell 1998; Givnish 2002) although plasticity can be found even in floral development (Walbot 1996). The best known case of seasonal floral plasticity is the development of cleistogamous flowers (completely closed and therefore self-pollinating flowers) in many species following the failure of pollination earlier in the season. The plasticity inherent in facultatively cleistogamous species was known to Linnaeus and to Darwin who noted that this variability was due to environmentally correlated factors. "Mr Scott informs me that in India it [Viola roxburghiana] bears perfect flowers only during the cold season, and that these are quite fertile. During the hot, and more especially during the rainy season, it bears an abundance of cleistogamic flowers.": Darwin (1877).

Animals are advantaged by the presence of a CNS which gives them considerable flexibility of response, while plants have to achieve plasticity despite the absence of a CNS. Givnish (2002) speculated that the rate of capture of energy by plants may be too low to select for the maintenance of costly neural networks with centralized machinery. Furthermore, plants also have to contend with the problem of competition between their own units for light. For example, faster energy capture by leaves may result in those leaves being overtopped by new leaves as more photosynthate is made available, resulting in a shorter leaf lifespan as these leaves are so shaded that they can no longer contribute to positive carbon gain (Reich et al 1992). In the absence of a neural network, plants also have to rely on relatively slower intra-plant communication via hormones (Berleth and Sachs 2001) or via RNA and peptides through the symplast (however, see LevYadun 2001). It would be extremely valuable to compare the net rates of energy gain in plants and in sessile plantlike animals that also photosynthesise, such as sponges and colonial coelenterates that form corals, to examine the costs and benefits of relatively fixed versus relatively plastic strategies. These colonial animals also do not have a CNS, are modular in organization, and therefore could be considered to exist at the boundary between the plant and animal phenotype. To my knowledge, no serious attempt has been made to compare the plasticity of these specific groups, and this may have to do with the difficulty of culturing corals and sponges under controlled conditions (Merks et al 2004). However, there is now evidence that, just like plants, sessile hydroids produce shoot-like apical meristems that maintain totipotency without further differentiation (Berking et al 2002) and that colonial hydroids adopt sheet-like growth in resource-rich areas to capture maximal resources while they produce runner-like stolons to effect movement of the colony away from resource-poor areas (Blackstone 1999). This is exactly how plants forage. Attempts to model branching in marine modular sessile organisms are also now being made (Sánchez and Lasker 2003; Sánchez et al 2004) in order to understand how such sessile animals deal with the plant-like phenomenon of self-shading and its effect on resource capture (Kim and Lasker 1998).

There are, however, certainly some types of plastic solutions available to animals that plants cannot adopt. I will cite one example that will illustrate the point. In this example, the desired phenotype is temporarily achieved by behavioural means, and is only subsequently acquired by the activity of specific genes (Montgomerie et al 2001; Piersma and Drent 2003). In the tundra environment, male and female rock ptarmigans have drab cryptic summer plumages and white winter feathers to provide camouflage against the seasonally-changing background. Males, however, undergo a moult from winter white to summer brown plumage later in the year than females because females prefer to mate with white-plumaged males. However, once mating is over, males are released from the selective pressure to remain white as ordained by sexual selection and begin to moult under correlated or separate signals from reproductive physiology and photoperiod. However, since moulting is a prolonged process during which males are conspicuous and vulnerable to predators, males rapidly acquire the appropriate dark plumage by deliberately soiling their feathers. Thus males achieve camouflage by behavioural means while their summer moult is completed. This type of behavioural acquisition of a subsequent developmentally-acquired morphological trait is surely unique to animals.

Ever since the origin of life on earth, life forms have been exposed to stress and have been under selection for their ability to cope with stress, for which plasticity-generating mechanisms may have been extremely important adaptations. An inter-disciplinary approach that studies the phenotype from the organismal level down to the signalling and response molecules shows great promise in addressing the costs and benefits of phenotypic plasticity and thus the true nexus between phenotype and genotype (e.g. Waterland and Jirtle 2004) in plants and animals. Furthermore, in addition to asking which traits are plastic, it is invaluable to ask which traits are not. This approach should provide insights into the selection pressures, developmental constraints, and molecular machinery that govern phenotypic plasticity in plants and animals, and will also perhaps make the divide between plants and animals even fuzzier at the functional level than it is at the present time.

\section{Acknowledgements}

The comments by Patrick Bateson and two anonymous reviewers of this manuscript are gratefully acknowledged. 


\section{References}

Abdrakhamanova A, Wang Q Y, Khokhlova L and Nick P 2003 Is microtubule disassembly a trigger for cold acclimation?; Plant Cell Physiol. 44 676-686

Agrawal A A 2001 Phenotypic plasticity in the interactions and evolution of species; Science 294 321-325

Agrawal A A, Laforsch C and Tollrian R 1999 Transgenerational induction of defences in animals and plants; Nature (London) 401 60-64

Allen G J, Chu S P, Harrington C L, Schumacher K, Hoffmann T, Grill E and Schroeder J I 2001 A defined range of guard cell calcium oscillation parameters encodes stomatal movements; Nature (London) 411 1053-1058

Baldwin I T and Schultz J C 1983 Rapid changes in tree leaf chemistry induced by damage: evidence for communication between plants; Science 221 277-279

Ballaré C L 1999 Keeping up with the neighbours: phytochrome sensing and other signalling mechanisms; Trends Plant Sci. 4 97-102

Baluška F, Hlavacka A, Volkmann D and Menzel D 2004 Getting connected: actin-based cell-to-cell channels in plants and animals; Trends Cell Biol. 14 404-408

Barrier M, Robichaux R H and Purugganan M D 2001 Accelerated regulatory gene evolution in an adaptive radiation; Proc. Natl. Acad. Sci. USA 98 10208-10213

Berking S, Hesse M and Herrmann K 2002 A shoot meristemlike organ in animals; monopodial and sympodial growth in Hydrozoa; Int. J. Dev. Biol. 46 301-308

Berleth T and Sachs T 2001 Plant morphogenesis: long-distance coordination and local patterning; Curr. Opin. Plant Biol. 4 5762

Bhalla U S and Iyengar R 1999 Emergent properties of networks of biological signaling pathways; Science 283 381-387

Bhalla U S, Ram P T and Iyengar R 2002 MAP kinase phosphatase as a locus of flexibility in a mitogen-activated protein kinase signaling network; Science 297 1018-1023

Blackstone N W 1999 Redox control in development and evolution: evidence from colonial hydroids; J. Exp. Biol. 202 $3541-3553$

Bliss T V P and Collingridge G L 1993 A synaptic model of memory: long-term potentiation in the hippocampus; Nature (London) 361 31-39

Borges R M, Gowda V and Zacharias M 2003 Butterfly pollination and high-contrast visual signals in a low-density distylous plant; Oecologia 136 571-573

Bradshaw A D 1965 Evolutionary significance of phenotypic plasticity in plants; Adv. Genet. 13 115-155

Bray D 1995 Protein molecules as computational elements in living cells; Nature (London) 376 307-312

Bruin J, Sabelis M W and Dicke M 1995 Do plants tap SOS signals from their infested neighbours?; Trends Ecol. Evol. 10 167-170

Buss L W 1987 The evolution of individuality (Princeton: Princeton University Press)

Charnov E L 1976 Optimal foraging, the marginal value theorem; Theor. Popu. Biol. 9 129-136

Cock J M, Vanoosthuyse V and Gaude T 2002 Receptor kinase signaling in plants and animals: distinct molecular systems with mechanistic similarities; Curr. Opin. Cell Biol. 14230 236

Cremer S and Heinze J 2003 Stress grows wings: environmental induction of winged dispersal males in Cardiocondyla ants; Curr. Biol. 13 219-223
Cresswell J E 1998 Stabilising selection and the structural variability of flowers; Ann. Bot. 81 463-473

Darwin C 1877 The different forms of flowers on plants of the same species; (London: John Murray)

Dempsey D, Shah J and Klessig D F 1999 Salicylic acid and disease resistance in plants; Crit. Rev. Plant Sci. 18 547-575

Diggle P K 1997 Ontogenetic contingency and floral morphology: the effects of architecture and resource limitation; Int. J. Plant Sci. 158 S99-S107

Diggle P K 2002 A developmental morphologist's perspective on plasticity; Evol. Ecol. 16 267-283

Ding B, Itaya A and Qi Y 2003 Symplasmic protein and RNA traffic: regulatory points and regulatory factors; Curr. Opin. Plant Biol. 6 596-602

Dong X 2001 Genetic dissection of systemic acquired resistance; Curr. Opin. Plant Biol. 4 309-314

Fankhauser C 2002 Light perception in plants: cytokinins and red light join forces to keep phytochrome B active; Trends Plant Sci. 7 143-145

Farmer E E and Ryan C 1990 Interplant communication: airborne methyl jasmonate induces synthesis of proteinase inhibitors in plant leaves; Proc. Natl. Acad. Sci. USA 877713 7716

Fasano J M, Massa G D and Gilroy S 2002 Ionic signaling in plant responses to gravity and touch; J. Plant Growth Regul. $2171-88$

Firn R D and Jones C G 1995 Plants may talk, but can they hear?; Trends Ecol. Evol. 10371

Fowler S V and Lawton J H 1985 Rapidly induced defences and talking trees: The devil's advocate position; Am. Nat. 126 181195

Genoud T and Métraux J-P 1999 Crosstalk in plant cell signaling: structure and function of the genetic network; Trends Plant Sci. 4 503-507

Gil D, Graves J, Hazon N and Wells A 1999 Male attractiveness and differential testosterone investment in zebra finch eggs; Science 286126-128

Gilroy S and Trewavas A 2001 Signal processing and transduction in plant cells: the end of the beginning?; Nature Rev. Mol. Cell Biol. 2 307-314

Givnish T J 2002 Ecological constraints on the evolution of plasticity in plants; Evol. Ecol. 16 213-242

Golden J W and Riddle D L 1984 The Caenorhabditis elegans dauer larva: developmental effects of pheromone, food, and temperature; Dev. Biol. 102 368-378

Greengard P 2001 The neurobiology of slow synaptic transmission; Science 294 1024-1029

Grime J P, Campbell B D, Mackey J M L and Crick J C 1991 Root plasticity, nitrogen capture and competitive ability; in Plant root growth: an ecological perspective. (ed.) D Atkinson (Oxford: Blackwell) pp 381-397

Grime J P and Mackey J M L 2002 The role of plasticity in resource capture in plants; Evol. Ecol. 16 299-307

Harmon A C, Gribskov M and Harper J F 2000 CDPKs - a kinase for every $\mathrm{Ca}^{2+}$ signal; Trends Plant Sci. 5 154-159

Harvey J A, Corley L S and Strand M R 2000 Competition induces adaptive shifts in caste ratios of a polyembryonic wasp; Nature (London) 406 183-186

Holt B F III, Hubert D A and Dangl J L 2003 Resistance gene signaling in plants - complex similarities to animal innate immunity; Curr. Opin. Immunol. 15 20-25

Horvath D P, Anderson J V, Chao W S and Foley M E 2003 Knowing when to grow: signals regulating bud dormancy; Trends Plant Sci. 8 534-540 
Huey R B, Carlson M, Crozier L, Frazier M, Hamilton H, Harley C, Hoang A and Kingsolver J G 2002 Plants versus animals: do they deal with stress in different ways?; Integ. Comp. Biol. 42 415-423

Ingolia N T and Murray A W 2002 History matters; Science 297 948-949

Jablonka E, Lamb M and Avital E 1998 'Lamarckian' mechanisms in Darwinian evolution; Trends Ecol. Evol. 13 206-210

Kandel E R 2001 The molecular biology of memory storage: a dialogue between genes and synapses; Science 294 1030-1038

Karban R, Agrawal A A, Thaler J S and Adler L S 1999 Induced plant responses and information content about risk of herbivory; Trends Ecol. Evol. 14 443-447

Karban R, Baldwin I T, Baxter K J, Laue G and Felton G W 2000 Communication between plants: induced resistance in wild tobacco plants following clipping of neighboring sagebrush; Oecologia 125 66-71

Karniol B and Chamovitz D A 2000 The COP9 signalosome: from light signaling to general developmental regulation and back; Curr. Opin. Plant Biol. 3 387-393

Kasahara M, Kagawa T, Olkawa K, Suetsugu N, Miyao M and Wada M 2002 Chloroplast avoidance movement reduces photodamage in plants; Nature (London) 420 829-832

Kelly C K 1990 Plant foraging: a marginal value model and coiling response in Cuscuta subinclusa; Ecology 71 1916-1925

Kelly C K 1992 Resource choice in Cuscuta europaea; Proc. Natl. Acad. Sci. USA 89 12194-12197

Kim K and Lasker H R 1998 Allometry of resource capture in colonial cnidarians and constraints on modular growth; Funct. Ecol. 12 646-654

Kovalchuk I, Kovalchuk O, Kalck V, Boyko V, Filkowski J, Heinlein M and Hohn B 2003 Pathogen-induced systemic plant signal triggers DNA rearrangements; Nature (London) $\mathbf{4 2 3}$ 760-762

Leigh E G Jr 1977 How does selection reconcile individual advantage with the good of the group?; Proc. Natl. Acad. Sci. USA 74 4542-4546

Lerdau M 2002 Plants talk - but can they listen?; Science 298361

Levitan D R 1989 Density-dependent size regulation in Diadema antillarum: effects on fecundity and survivorship; Ecology 70 1414-1424

Lev-Yadun S 2001 Intrusive growth - the plant analog of dendrite and axon growth in animals; New Phytol. 150 508-512

Lin C 2000 Plant blue-light receptors; Trends Plant Sci. 5337 342

Losos J B, Creer D A, Glossop D, Goellner R, Hampton A, Roberts G, Haskell N, Taylor P and Ettling J 2000 Evolutionary implications of phenotypic plasticity in the hindlimb of the lizard Anolis sagrei; Evolution 54 301-305

Lucht J M, Mauch-Mani B, Steiner H-Y, Metraux J-P, Ryals J and Hohn B 2002 Pathogen stress increases somatic recombination frequency in Arabidopsis; Nature Genet. 30 311314

Merks R M H, Hoekstra A G, Kaandorp J A and Sloot P M A 2004 Polyp oriented modelling of coral growth; J. Theor. Biol. 228 559-576

Meyerowitz E M 1999 Plants, animals and the logic of development; Trends Cell Biol. 9 M65-M68

Meyerowitz E M 2002 Plants compared to animals: the broadest comparative study of development; Science 295 1482-1485

Mitchell-Olds T and Knight C A 2002 Chaperones as buffering agents?; Science 296 2348-2349

Money N P 2002 Mushroom stem cells; BioEssays 24 949952
Montgomerie R, Lyon B and Holder K 2001. Dirty ptarmigan: behavioral modification of conspicuous male plumage; $B e$ hav. Ecol. 12 429-438

Nakagaki T, Yamada H and Toth A 2000 Maze-solving by an amoeboid organism; Nature (London) 407470

Nottebohm F 1981 A brain for all seasons: cyclical anatomical changes in song control nuclei of the canary brain; Science 214 1368-1370

Novoplansky A 2002 Developmental plasticity in plants: implications of non-cognitive behavior; Evol. Ecol. 16 177-188

Piersma T and Drent J 2003 Phenotypic flexibility and the evolution of organismal design; Trends Ecol. Evol. 18 228-233

Pigliucci M 1996 How organisms respond to environmental changes: from phenotypes to molecules (and vice versa); Trends Ecol. Evol. 11 168-173

Pigliucci M 2002 Buffer zone; Nature (London) 417 598-590

Pineda-Krch M and Fagerström T 1999 On the potential for evolutionary change in meristematic cell lineages through intraorganismal selection; J. Evol. Biol. 12 681-688

Queitsch C, Sangster T A and Lindquist S $2002 \mathrm{Hsp} 90$ as a capacitor of phenotypic variation; Nature (London) 417 618624

Reich P B, Walters M B and Ellsworth D S 1992 Leaf life-span in relation to leaf, plant, and stand characteristics among diverse ecosystems; Ecol. Monogr. 62 365-392

Rutherford S L and Lindquist S 1998 Hsp90 as a capacitor for morphological evolution; Nature (London) 396 336-342

Sachs T 2002 Consequences of the inherent developmental plasticity of organ and tissue relations; Evol. Ecol. 16 243-265

Sánchez J A and Lasker H R 2003 Patterns of morphological integration in marine modular organisms: supra-module organization in branching octocoral colonies; Proc. R. Soc. London B270 2039-2044

Sánchez J A, Lasker H R, Nepomuceno E G, Sánchez J D and Woldenberg M J 2004 Branching and self-organization in marine modular colonial organisms: a model; Am. Nat. 163 E24-E39

Sangster T A, Lindquist S and Queitsch C 2004 Under cover: causes, effects and implications of Hsp90-mediated genetic capacitance; BioEssays 26 348-362

Schenk P M, Kazan K, Wilson I, Anderson J, Richmond T, Somerville S and Manners J M 2000 Coordinated plant defense responses in Arabidopsis revealed by microarray analysis; Proc. Natl. Acad. Sci. USA 97 11655-11660

Schlichting C A and Pigliucci M 1998 Phenotypic evolution: $a$ reaction norm perspective (Sunderland: Sinauer)

Schlichting C D and Smith S 2002 Phenotypic plasticity: linking molecular mechanisms with evolutionary outcomes; Evol. Ecol. 16 189-211

Schmitt J, Dudley S A and Pigliucci M 1999 Manipulative approaches to testing adaptive plasticity: phytochrome-mediated shade-avoidance responses in plants; Am. Nat. 154 S43-S54

Schnittger A, Jürgens G and Hülskamp M 1998 Tissue layer and organ specificity of trichome formation are regulated by GLABRA1 and TRIPTYCHON in Arabidopsis; Development 125 2283-2289

Schulze-Lefert P 2004 Plant immunity: the origami of receptor activation; Curr. Biol. 14 R22-R24

Silvertown J 1998 Plant phenotypic plasticity and non-cognitive behaviour; Trends Ecol. Evol. 13 255-256

Silvertown J and Gordon G M 1989 A framework for plant behavior; Annu. Rev. Ecol. Syst. 20 349-366

Simard S W, Perry D A, Jones M A, Myrold D D, Durall D M and Molina R 1997 Net transfer of carbon between ectomy- 
corrhizal tree species in the field; Nature (London) 388 579582

Sivaguru M, Pike S, Gassmann W and Baskin T I 2003 Aluminum rapidly depolymerizes cortical microtubules and depolarizes the plasma membrane: evidence that these responses are mediated by a glutamate receptor; Plant Cell Physiol. 44 $667-675$

Smith H 2000 Phytochromes and light signal perception by plants - an emerging synthesis; Nature (London) 407 585-591

Somanathan H, Borges R M and Chakravarthy V S 2004 Does neighborhood floral display matter? Fruit set in carpenter beepollinated Heterophragma quadriloculare and beetle-pollinated Lasiosiphon eriocephalus; Biotropica 36 139-147

Stamps J 2003 Behavioural processes affecting development: Tinbergen's fourth question comes of age; Anim. Behav. 66 $1-13$

Strong D R and Ray T S 1975 Host tree location behavior of a tropical vine (Monstera gigantea) by scototropism; Science $190804-806$

Sultan S E 2000 Phenotypic plasticity for plant development, function and life history; Trends Plant Sci. 5 537-542

Sword G A 1999 Density-dependent warning coloration; $\mathrm{Na}$ ture (London) 397217

Sword G A 2002 A role for phenotypic plasticity in the evolution of aposematism; Proc. R. Soc. London B269 1639-1644

Takahashi K, Isobe M, Knight M R, Trewavas A J and Muto S 1997 Hypoosmotic shock induces increases in cytosolic $\mathrm{Ca}^{2+}$ in tobacco suspension-culture cells; Plant Physiol. 113 587594

Thomas H 2002 Ageing in plants; Mechs. Ageing Dev. 123 747753

Tramontin A D and Brenowitz E A 2000 Seasonal plasticity in the adult brain; Trends Neurosci. 23 251-258

Trewavas A 1999a How plants learn; Proc. Natl. Acad. Sci. USA $964216-4218$

Trewavas A 1999b Le calcium, c'est la vie: calcium makes waves; Plant Physiol. 120 1-6

Trewavas A 2002 Mindless mastery; Nature (London) 415841

Trewavas A 2003 Aspects of plant intelligence; Ann. Bot. 92 1-20

Trewavas A and Malhó R 1997 Signal perception and transduction: the origin of the phenotype; Plant Cell 9 1181-1195
Tscharntke T, Thiessen S, Dolch R and Boland W 2001 Herbivory, induced resistance, and interplant signal transfer in $\mathrm{Al}$ nus glutinosa; Biochem. Syst. Ecol. 29 1025-1047

Via S, Gomulkiewicz R, de Jong G, Scheiner S M, Schlichting C D and van Tienderen P H 1995 Adaptive phenotypic plasticity: consensus and controversy; Trends Ecol. Evol. 10 212-217

von Strandmann E P, Nastos A, Holewa B, Senkel S, Weber H and Ryffel G U 1997 Patterning the expression of a tissuespecific transcription factor in embryogenesis: HNF1 alpha gene activation during Xenopus development; Mechs. Dev. $647-17$

Walbot V 1996 Sources and consequences of phenotypic and genotypic plasticity in flowering plants; Trends Plant Sci. 1 $27-32$

Wasteneys G O 2003 Microtubules show their sensitive nature; Plant Cell Physiol. 44 653-654

Wasteneys G O and Galway M E 2003 Remodeling the cytoskeleton for growth and form: an overview with some new views; Annu. Rev. Plant Biol. 54 691-722

Waterland R A and Jirtle R L 2004 Early nutrition, epigenetic changes at transposons and imprinted genes, and enhanced susceptibility to adult chronic diseases; Nutrition 20 63-68

West-Eberhard M J 2003 Developmental plasticity and evolution; (Oxford: Oxford University Press)

Wikelski M and Thom C 2000 Marine iguanas shrink to survive El Niño; Nature (London) $\mathbf{4 0 3} 37$

Wilson K 2000 How the locust got its stripes: the evolution of density-dependent aposematism; Trends Ecol. Evol. 15 88-90

Wu X, Weigel D and Wigge P A 2002 Signaling in plants by intercellular RNA and protein movement; Genes Dev. 16 151158

Yang T and Poovaiah B W 2003 Calcium/calmodulin-mediated signal network in plants; Trends Plant Sci. 8 505-512

Yang T, Segal G, Abbo S, Feldman M and Fromm H 1996 Characterization of the calmodulin gene family in wheat: structure, chromosomal location, and evolutional aspects. Mol. Gen. Genet. 252 684-694

Zhang H and Forde B G 1998 An Arabidopsis MADS box gene that controls nutrient-induced changes in root architecture; Science 279 407-409

ePublication: 30 November 2004 